\title{
Electronic thermodynamics part 1: Thermo- electromechanical system modeling, instrumentation, and simulation
}

Irving Morgado-González

Universidad Autónoma del Estado de Hidalgo

Jose Angel Cobos-Murcia ( $\nabla$ catseven78@gmail.com )

Universidad Autónoma del Estado de Hidalgo https://orcid.org/0000-0002-9946-5785

Marco Antonio Marquez-Vera

Universidad Politécnica de Pachuca

Omar Arturo Dominguez-Ramirez

Universidad Autónoma del Estado de Hidalgo

Article

Keywords:

Posted Date: January 13th, 2022

DOI: https://doi.org/10.21203/rs.3.rs-1247394/v1

License: @ (i) This work is licensed under a Creative Commons Attribution 4.0 International License.

Read Full License 


\section{Abstract}

This research proposes to obtain a mathematical model that describes the dynamic operation of a brushed DC motor, to obtain a state function considering the electrical, mechanical, and thermal effects of the DC motor. The dynamic evolution of the proposed function is evaluated by simulation using Matlab software, and by applying different values of the step type inputs for the brushed motor excitation employing pulse width modulation (PWM) to obtain a wide range of operations. Experimental results show that the developed state function, provides a reliable approximation to estimate the voltage, armature current, mechanical torque, and temperature of the brushed DC motor, showing an error percentage of $0.2 \%$.

\section{Introduction}

Brushed DC motors are the simplest and most popular electric machines widely used in industrial applications, electric vehicles, biomedical technologies, training and entertainment platforms, and robotics [1-7]. Easy speed and torque regulation, position control and uniform bearing tribology are characteristics of this electric machine; and from here, its multiple applications on experimental platforms. Nowadays, different authors have proposed many mathematical models by describing the brushed DC motor behavior that is crucial for: i) design of the electromechanical system, ii) the application as a source of torque, iii) design of electrical and mechanical protections, iv) fault diagnosis system, and v) design of the control law depending or not on the mathematical model [8-14]. Napoli [15] presented a general approach to DC motor modeling, using the finite element technique for magnetic analysis, in conjunction with tensor manipulation of the network parameters to simulate a desired degree of complexity. In addition, Suriano et al. [16] presented an article, they applied the tensor method to simulate the time-varying circuit topology of the armature winding of a DC motor, while Alvarado [8] modeled with non-homogeneous linear first-order differential equations with constant coefficients for speed control by armature current. Martinez [17] obtained mathematical models through transfer functions for velocity and position. Other attractive techniques for modeling DC motors were developed by Padre-Ñonthe et al. [18]. They proposed Takagi-Sugeno (T-S) type fuzzy modeling techniques based on the aggregation of linear sub-models from transfer functions that define the system dynamics at different operating points. In this context, the brushed motor is modeled as an RL series circuit with a voltage source generated in the motor armature $[19,20]$. However, the performance of a DC motor depends not only on the load torque and the structure of the control law; also, of the parametric changes that occur with the operating time. A determining factor is temperature, both due to the Joule effect and the dynamic friction in bearings [21-26]. To this end, adaptive control techniques are considered to regulate the output, despite the parametric uncertainty [27]; nevertheless, the precision of the control depends on the mathematical model, partially defined in its structure [28].

In the present work, a new mathematical model approach is proposed to estimate the thermoelectromechanical behavior of a brushed DC motor through a state function formulation. Based on the electronic thermodynamic properties of the motor. The following sections introduce the basic structure of 
the brushed DC motor and, at the same time, a state function is proposed that considers the equivalent electrical, mechanical and thermal action. This thermo-electromechanical state function was used as a starting point to evaluate the dynamic system of the brushed DC motor for different operating ranges. The validation of the state function experimentally is also presented.

\section{Material And Methods}

\subsection{Variables in the thermodynamic system of a brushed DC motor}

As thermodynamic variables in the electrical conduction of a conducting wire in a brushed DC motor (BDCM); the electric potential $(V)$ and temperature $(T)$, which are considered intensive variables, while the electric current of the armature $\left(I_{a}\right)$, and the mechanical torque $\left(T_{m}\right)$ as extensive variables. Starting with the equation of Kirchhoff's voltage law (equation 1), which indicates that the sum of voltages around a path or closed circuit must be zero and mathematically is expressed as:

$$
\sum_{i=1}^{n} V_{i}=0
$$

Wherenis the total number of voltages measured in a closed-loop.

\subsection{Mathematical modeling of a BCDM}

Figure 1 shows the basic circuit of a $B D C M$. It describes a series circuit consisting of an armature resistance $R_{a}$, an armature inductance $L_{a}$, and the counter-electromotive force $V_{a}$ generated in the armature when the rotor turns.

By analyzing the equivalent circuit mesh of the series BDCM, considering Equation 1 and Ohm's law, we can express the voltage drop terms of the circuit components. Where $V$ is the supplied voltage, $V_{R_{a}}$ is the voltage across a resistor, $V_{L_{a}}$ is the voltage across an inductor, and $V_{a}$ is the counter-electromotive force.

$$
V-V_{R_{a}}-V_{L_{a}}-V_{a}=0
$$

The voltage across a resistor $V_{R_{a}}$ is expressed according to Equation 3 , where $I_{a}$ is the armature current and $R_{a}$ is the armature resistance. The voltage on an inductor $V_{L_{a}}$ is expressed according to Equation 4, where $L_{a}$ is the armature inductance. Here, the counter-electromotive force $V_{a}$ is expressed according to Equation 5 , where $K_{b}$ is the torque constant, and $\dot{\theta}$ is the angular velocity [20]. 


$V_{\boldsymbol{R}_{\mathbf{a}}}=I_{\mathbf{a}} \boldsymbol{R}_{\mathbf{a}}$
$V_{L_{a}}=L_{a}{ }^{d\left(I_{a}\right)}$
$V_{a}=K_{b} \theta$

\subsection{Equations to describe the behavior of the BDCM.}

To establish a state function that provides for the thermodynamic variables considered, it is necessary to establish that the electric torque $T_{m}$ developed by the motor, which is expressed by Equation 6 , where $K_{a}$ and $I_{a}$ represent the torque constant, and the armature current. Whereas $K_{b} \approx K_{a}$ in steady-state, solving and equating with Equation 5, we obtain the counter-electromotive force $V_{a}$ (Equation 7) expressed in terms of the electric torque $T_{m}$ and the armature current $I_{a}$ [20].

$\boldsymbol{T}_{\boldsymbol{m}}=\boldsymbol{K}_{\boldsymbol{a}} \boldsymbol{I}_{\mathbf{a}}$
$V_{a}=\frac{T_{m}}{I_{a}}$

On the other hand, to express the armature resistance $R_{a}$ in terms of temperature [29], we use Equation 8, which can be expressed in its differential form in Equation 9, and finally, obtain a function in (Equation 10) that expresses the dependence on the resistance on the temperature.

\begin{tabular}{|l|}
$\boldsymbol{R}_{\boldsymbol{a}}=\boldsymbol{R}_{\mathbf{0}}\left[\mathbf{1}+\boldsymbol{\alpha}\left(\boldsymbol{T}_{\boldsymbol{f}}-\boldsymbol{T}_{\mathbf{i}}\right)\right]$ \\
$d R_{a}=\alpha R_{0} d T$ \\
$R_{a}=\alpha R_{0} T$
\end{tabular}

Where $\alpha$ is the thermal constant of the BDCM armature copper $\left(0.004^{\circ} \mathrm{C}^{-1}\right)$ [29], $T$ is the room temperature at $20^{\circ} \mathrm{C}$, and $R_{0}=115 \Omega$ the resistance of the motor armature copper measured at temperature $T$.

\subsection{Power (P) and Work (W) of the BDCM system.}

The power $P$ is the amount of work $W_{E l e C}$ done per unit time (Equation 11), taking into consideration that the charge of an electric current is: $q=I_{a} t$ and integrating, we obtain the equation for electric work described in Equation 12. Finally, $W_{E l e c}$ is considered to be the sum of all work contributions (Equation 13). 


$\boldsymbol{P}_{\text {Elec }}=\frac{d W_{\text {Elec }}}{d t}=V \boldsymbol{I}_{\mathbf{a}}$
$W_{\text {Elec }}=V q$
$W_{\text {Elec }}=W_{\text {Mag }}+W_{\text {Thermal }}+W_{M e c}$

\subsection{Implementation of the adiabatic BDCM system for study and data acquisition.}

The verification of the theoretical model developed was carried out by validating it with practical experimental data, which were acquired through an adiabatic system that also allows obtaining the thermo-electromechanical parameters of the BDCM.

The system is presented in Fig. 2 and consists as shown in Fig. $<$ link rid="fig2" $>2</$ link $>a$, 1, and 2, a box and its lid made of expanded polystyrene (EPS). Due to its insulating properties, it is suitable to avoid heat exchanges between the inside and outside [30]. Into the box of Fig. 2a, 3 is the power supply, 4 an Arduino Uno microcontroller board, 5 a BDCM controller system (H-bridge), which are the simplest modules that provide the power amplification for the low-level control signals, such as PWM and direction supplied by the user.

Moreover, for current measurement (Figure 2a), point 6 shows the Allegro ACS711LC bidirectional Halleffect current sensor to record the motor current by issuing an analog voltage that is linearly proportional to the input current. This type of sensor is used in several applications such as closed-loop torque, speed, and position control for BDCM as shown in [31-34].

Whereas, inside the box (Figure 2b); 7, metal gearbox; 8, brushed DC motor; 9, quadrature encoder; 10 , motor temperature sensor, and 11, a sensor to measure the internal temperature of the box, is placed inside the box.

Finally, on the outside of the box, point 12 is a sensor for external temperature monitoring. In all cases, the temperature is measured by a resistive sensor HMZ-433A1.

Data acquisition from the temperature and current sensors are processed using an "Arduino Uno" microcontroller from analog signals. Therefore, three functions are programmed for each temperature (internal, external, and motor). Likewise, functions of the motor current and the pulse reading of the motor encoder are assigned. In addition, the control signal for pulse width modulation (PWM) is programmed in the "Arduino Uno" microcontroller, using five different PWM percentage conditions; 20, 40, 60, 80, and 100. It is sent to the motor controller with a data acquisition time of 15 min for each PWM percentage value.

Figure 3 shows the general scheme proposed for this study. The power supply voltage of the motor is $12 \mathrm{~V}$ and $5 \mathrm{~V}$ for all the sensors employed, which is provided from a fixed linear voltage AC-DC switched-power supply. The BDCM used for this study is a 37D metal gear-motor, with a gear-ratio of 131:1. An encoder 
integrated on the motor shaft consisting of two Hall-effect sensors used to sense the rotation of a magnetic disk, with a resolution of $64 \mathrm{CPR}$. Although the measurement of the armature resistance and armature inductance of the BDCM can be obtained by the method shown in [35], in this work, they were obtained directly with a DE-5000 LCR device (not shown in Figure 2) that allowed to obtain values between $9.20 \Omega$ and $1.803 \mathrm{mH}$, respectively.

Programming for data acquisition was performed in a script using MATLAB 13.0 software, within a script, using loops in certain sections of the code to perform iterative calculations, with which it is possible to simultaneously determine both recorded and calculated variables.

\section{Thermal, Mechanical, And Electronic Properties Of A Bcdm 3.1. Equation of state}

Equation (14) shows the mathematical model that is proposed in this work, which represents an equation of state that relates the variables that are considered in this study of a BDCM system. With this mathematical model, it is possible to determine the contribution of each element that has been considered within the circuit, both for the electrical power $P$ (Equation 15) and for the work $W$ (Equation 16).

$V=\alpha T R_{0} I_{a}+\frac{1}{2 q} L_{a} I_{a}^{2}+\frac{1}{q} T_{m}^{\theta}$
$P_{E l e c}=V I_{a}=\alpha I_{a}^{2} R_{0} T+I_{a} L_{a} \frac{d\left(I_{a}\right)}{d t}+T_{m} \theta$
$W_{E l e c}=V q=\alpha T R_{0} I_{a} q+\frac{1}{2} L_{a} I_{a}^{2}+T_{m} \theta$

Figure 4 shows the value of the electrical power calculated using Equation (15). It can be observed (Fig. 4a) the three contributions and the total calculated power which presents a value of $1.7649 \mathrm{~W}$, while the electrical, magnetic, and mechanical contributions show values of $0.2981 \mathrm{~W}, 0.0 \mathrm{~W}$, and $1.4669 \mathrm{~W}$. The mechanical contribution is the largest followed by the electrical supply, and finally, the magnetic is null in steady state. Likewise, it is possible to obtain the electrical power values by operating the PWM at different percentages of its nominal capacity. Fig. $4 \mathrm{~b}$ shows the power transients at five different PWM\% values, and it is observed that the power presents a first-order dependence to the PWM\%.

Figure 5 shows the calculated work value using Equation (16), and Fig. 5a shows the three contributions during operation at $100 \%$ of the PWM rated capacity. The total calculated work is $1,582.7 \mathrm{~kW}$, while the thermal, magnetic, and mechanical contributions show values of $267.79 \mathrm{~W}, 29.2 \mu \mathrm{W}$, and 1,315 kW, during the $100 \%$ operation of the PWM. The mechanical contribution is the largest, followed by the electrical and finally the magnetic. Likewise, it is possible to obtain the electrical work values when 
operating the PWM at different percentages of its nominal capacity. Fig. 5b shows the work transitory, and it can be observed that the work presents a first-order dependence to the PWM\%.

\subsection{Estimation of thermo-electromechanical variables of the BDCM.}

Given that the state function represents the dependence of the electric potential ( $V$ ) on changes in electric current $\left(I_{a}\right)$, temperature $(T)$ and torque $\left(T_{m}\right)$. It is established that $V=V\left(I_{a}, T, T_{m}\right)$ which gives the total differential (Equation 17). In the same way, $I_{a}=I_{a}\left(V, T, T_{m}\right)$ (Equation 18), $T=T\left(V, I_{a}, T_{m}\right)$ (Equation 19) and $T_{m}=T_{m}\left(V, I_{a}, T\right)$ (Equation 20) can be expressed.

$$
\begin{aligned}
& d V=\left(\frac{\partial V}{\partial I_{a}}\right)_{T, T_{m}} d I_{a}+\left(\frac{\partial V}{\partial T}\right)_{I_{a}, T_{m}} d T+\left(\frac{\partial V}{\partial T_{m}}\right)_{T, I_{a}} d T_{m} \\
& d I_{a}=\left(\frac{\partial I_{a}}{\partial V}\right)_{T, T_{m}} d V+\left(\frac{\partial I_{a}}{\partial T}\right)_{V, T_{m}} d T+\left(\frac{\partial I_{a}}{\partial T_{m}}\right)_{T, V} d T_{m} \\
& d T=\left(\frac{\partial T}{\partial V}\right)_{I_{a}, T_{m}} d V+\left(\frac{\partial T}{\partial I_{a}}\right)_{V, T_{m}} d I_{a}+\left(\frac{\partial T}{\partial T_{m}}\right)_{V, I_{a}} d T_{m} \\
& d T_{m}=\left(\frac{\partial T_{m}}{\partial V}\right)_{I_{a}, T} d V+\left(\frac{\partial T_{m}}{\partial I_{a}}\right)_{V, T} d I_{a}+\left(\frac{\partial T_{m}}{\partial T}\right)_{V, I_{a}} d T
\end{aligned}
$$

To obtain the corresponding values of the electrical material properties from the partial derivatives. The derivatives for each variable are obtained using the equation of state (see Equation 14), and subsequently using Maxwell's equations, the values of the partial derivatives of Equations (18), (19), and (20) are obtained.

With the differential equations solutions is possible to establish the values of each of the variables, as shown in Fig. 6, where the values were obtained using the adiabatic BDCM system, and the value calculated using the mathematical model of the variables: Voltage (3a), Current (3b), Temperature (3c) and Torque (3d), during the operation at $20,40,60,80$ and $100 \%$ of the nominal capacity of the PWM.

Figure 7 shows the percentage accuracy of the mathematical model for all the parameters evaluated. The voltage presents a higher variability during the first moments due to the motor start impulse and then stabilizes, reaching a $0.2 \%$ error in the measured signal. Current, temperature, and torque, on the other hand, present a better response with an average value of $100 \pm 0.1 \%$. 
The equations to obtain the values of the thermo-electromechanical variables are shown below.

\subsubsection{Voltage calculation}

From the solution of Equation 17, we obtain Equation 21, which represents the variation of the electric potential as a function of changes in current, temperature, and torque.

$$
\Delta V=\frac{L_{a}}{2 q}\left[I_{a_{2}}{ }^{2}-I_{a_{1}}{ }^{2}\right]+\alpha R_{0} T\left[I_{a_{2}}-I_{a_{1}}\right]+\alpha R_{0} T\left[T_{2}-T_{1}\right]+\frac{\theta}{q}\left[T_{m_{2}}-T_{m_{1}}\right]
$$

The BDCM system voltage operates as expected with a first-order linear increase between PWM\% and Voltage (Figure 6a), presenting a rate of change of $91.62 \mathrm{mV} / \mathrm{PWM} \%$ and a correlation $\left(\mathrm{r}^{2}\right)$ of 0.9922 . The values obtained by the model fit the measured voltage values, with an average coefficient of variation of 0.9855 (Fig. 7).

Figure 8 shows the voltage value estimated using Equation (14), showing the three contributions, during operation at $100 \%$ of the PWM rated capacity. The total calculated voltage is $9.7876 \mathrm{~V}$, while the electrical, magnetic, and mechanical contributions show values of $1.656 \mathrm{~V}, 48.67 \mu \mathrm{V}$, and $8.132 \mathrm{~V}$. The mechanical contribution is the highest followed by the electrical and finally the magnetic contribution.

\subsubsection{Current calculation}

From the solution of Equation (18), we obtain Equation (22), which represents the variation of current as a function of changes in voltage, temperature, and torque.

$$
\Delta I_{a}=\frac{q}{I_{a} L_{a}+\alpha R_{0} T}\left[V_{2}-V_{1}\right]-I_{a} \ln \left[\frac{I_{a} L_{a}+\alpha R_{0} T_{2}}{I_{a} L_{a}+\alpha R_{0} T_{1}}\right]-\frac{\theta}{I_{a} L_{a}+\alpha R_{0} T}\left[T_{m_{2}}-T_{m_{1}}\right]
$$

The current of the BDCM system operating as expected with a first-order linear increase between PWM\% and current (Fig. 6b), presenting a rate of change of $1.04 \mathrm{~mA} / \mathrm{PWM} \%$ and a correlation $\left(\mathrm{r}^{2}\right)$ of 0.9991 . The values obtained by the model fit the measured current values, with an average coefficient of variation of 1.0002 (Fig. 7 and 9).

\subsubsection{Temperature calculation}

The solution of Equation 19 gives Equation 23, which represents the variation of temperature as a function of changes in voltage, current, and torque. 


$$
\Delta T=\frac{\left[V_{2}-V_{1}\right]}{\alpha R_{0} I_{a}}-\frac{L_{a}}{\alpha R_{0} q}\left[I_{a_{2}}-I_{a_{1}}\right]-\operatorname{Tln}\left[\frac{I_{a_{2}}}{I_{a_{1}}}\right]-\frac{\theta}{\alpha R_{0} I_{a} q}\left[T_{m_{2}}-T_{m_{1}}\right]
$$

Figure $6 \mathrm{c}$ shows the comparison between the temperature records using the adiabatic BDCM system and the value calculated using the mathematical model of equation 23. It is observed that the values obtained by the model fit the measured temperature values, with an average variability coefficient of 0.99913 between the measured value and the modeled one. However, they do not present a first-order dependence concerning the PWM\%. Nevertheless, it is possible to observe two regions of average temperature.

It is possible to observe in Fig. 10, the BDCM system operates in two conditions, in low conditions for values lower than 40 of PWM\%, with a recorded temperature of $31.85 \pm 0.29^{\circ} \mathrm{C}$ and an average calculated temperature of $31.90 \pm 0.21^{\circ} \mathrm{C}$. While at values above 60 of PWM\% a temperature of $37.74 \pm 0.90$ and a calculated temperature of $37.75 \pm 0.91^{\circ} \mathrm{C}$ are recorded.

Figure 11 shows the value of the temperature calculated using Equation (23). Although, it would be possible to show the contributions to the temperature since the mathematical expression allows it. It has no physical representation, so the temperature cannot be considered in this way, being an intensive property that reaches quasi-stationary states, and the different heat capacities and heat transfer rate of the materials.

On the other hand, the heat given depends on each contribution of the given amount of heat, but that analysis will be left pending for a later part of this series of articles.

\subsubsection{Torque calculation}

Solving Equation (20) results in Equation (24), which represents the variation of torque as a function of changes in voltage, temperature, and current.

$$
\Delta T_{m}=\frac{q}{\theta}\left[V_{2}-V_{1}\right]-\frac{L_{a}}{2 \theta}\left[I_{a_{2}}{ }^{2}-I_{a_{1}}{ }^{2}\right]-{ }_{\bar{\theta}}^{\alpha R_{0} T q}\left[I_{a_{2}}-I_{a_{1}}\right]-{ }_{\bar{\theta}}^{\alpha R_{0} I_{a} q}\left[T_{2}-T_{1}\right]
$$

Figure 12 shows the comparison between the torque records using the adiabatic BDCM system and the value calculated using the mathematical model of Equation (24). It can be observed that the values obtained by the model fit the measured torque values, with an average variability coefficient of 1.00021 between the measured value and the modeled one. Furthermore, it can be observed that the current of the CD Brushed system operates as expected with a first-order linear increase, presenting a rate of change of $1.04 \mu \mathrm{Nm} / \mathrm{PWM} \%$ and a correlation $\left(\mathrm{r}^{2}\right)$ of 0.9579 .

Finally, this work does not consider a load connected to the motor shaft. Although, the model considers that the systems are in an equilibrium system under static conditions. Therefore, when a load is 
connected to the brushed DC motor system, the other variables must change to keep the required torque constant.

\section{Conclusions}

The main purpose of this first part is the mathematical model development that describes the relationship between all the variables, which allows it to be a thermodynamic state function of the BDCM system. Also, to establish the definitions of work and power, establishing the contribution of the magnetic, mechanical, and thermal components in these definitions. With this, it was possible to record, iteratively simulate and validate the values of the operating variables, such as current, voltage, torque, and temperature, which are estimated by the mathematical model with an error coefficient of less than $0.2 \%$ concerning those evaluated experimentally. Likewise, it was determined that the motor operates efficiently by showing a linear dependence of the voltage, current, and torque with the PWM supply.

Furthermore, it is understood the importance that the mathematical model can have in robotics control, automation, and fault diagnostics. In addition, the methodology used for the mathematical model development can be used to evaluate other electronic components and circuits in a similar way to the brushed DC motor.

Although, in future works, it is planned to present thermo-electromechanical coefficients and heat, as properties that establish the operating characteristics of this system, as well as, to present later thermodynamic properties such as enthalpy, entropy, and free energies of this system.

It is also contemplated that is possible to study other parameters related to the studied variables to evaluate their application in systems in realistic environments.

\section{References}

1. A. Muetze and Y. C. Tan, "Modeling and analysis of the technical performance of DC-motor electric bicycle drives based on bicycle road test data," Proc. IEEE Int. Electr. Mach. Drives Conf. IEMDC 2007, vol. 2, pp. 1574-1581, 2007, doi: 10.1109/IEMDC.2007.383663.

2. A. A. A. Emhemed and R. Bin Mamat, "Modelling and simulation for Industrial DC Motor using Intelligent control," Procedia Eng., vol. 41, no. Iris, pp. 420-425, 2012, doi:

10.1016/j.proeng.2012.07.193.

3. S. M. Orozco-Soto, J. C. Ramos-Fernández, and A. García-Barrientos, "Parametric Identification of a 3 DOF Robot Manipulator Using a DSP," 1st Int. Congr. Instrum. Appl. Sci., no. March 2015, pp. 1-9, 2010.

4. Lugo-Villeda M.A., Ruiz-Sanchez F.J., Dominguez-Ramirez O.A., Parra-Vega V. "Robotic Design of an Upper Limb Exoskeleton for Motion Analysis and Rehabilitation of Paediatric Neuromuscular

Disorders," In: Pons J., Torricelli D., Pajaro M. (eds) Converging Clinical and Engineering Research on 
Neurorehabilitation. Biosystems \& Biorobotics, vol 1. Springer, Berlin, Heidelberg., 2013, doi: doi.org/10.1007/978-3-642-34546-3_42

5. Guo, H., Sun, Q., Wang, C., Wang, Q., \& Lu, S. "A systematic design and optimization method of transmission system and power management for a plug-in hybrid electric vehicle," Energy, vol. 148, pp. 1006-1017, 2018, doi: doi.org/10.1016/j.energy.2018.01.152

6. Gao, B., Chen, H., Liu, Q., \& Chu, H. "Position control of electric clutch actuator using a triple-step nonlinear method," IEEE Transactions on Industrial Electronics, vol. 61, no. 12, pp. 6995-7003, 2014 doi: 10.1109/TIE.2014.2317131

7. Picaza, C. A., Pisarello, M. I., \& Monzón, J. E., "Analysis of the stability control of motors used in biomechanical prostheses". In VII Latin American Congress on Biomedical Engineering CLAIB 2016, Bucaramanga, Santander, Colombia, October 26th-28th, pp. 561-564, 2016. Springer, Singapore., doi: doi.org/10.1007/978-981-10-4086-3_141

8. M. Sebastian and A. Alvarado, "Modelo matemático de un motor de corriente continua separadamente excitado: Control de velocidad por corriente de armadura," Lat. Am. J. Phys. Educ, vol. 6, no. 1, pp. 155-161, 2012.

9. S. C. Maheriya and P. A. Parikh, "A Review: Modelling of Brushed DC Motor and Various Type of Control Methods," J. Res., vol. 1, no. 12, pp. 18-23, 2016.

10. J. Chotai and K. Narwekar, "Laboratory: Modelling and Position Control of a Brushed DC Motor," IEEE Proc. Electr. Power Appl., pp. 1-8, 2017, doi: 10.1109/ICAC3.2017.8318792

11. X. Wang, W. Wang, L. Li, J. Shi and B. Xie, "Adaptive Control of DC Motor Servo System With Application to Vehicle Active Steering," IEEE/ASME Transactions on Mechatronics, vol. 24, no. 3, pp. 1054-1063, June 2019, doi: 10.1109/TMECH.2019.2906250.

12. J. Scott, J. McLeish and W. H. Round, "Speed Control With Low Armature Loss for Very Small Sensorless Brushed DC Motors," in IEEE Transactions on Industrial Electronics, vol. 56, no. 4, pp. 1223-1229, April 2009, doi: 10.1109/TIE.2008.2007046.

13. Ghosh, M., Ghosh, S., Saha, P. K., and Panda, G. K., "Semi-analytical dynamic model of permanentmagnet direct current brushed motor considering slotting effect, commutation, and PWM-operated terminal voltage," IEEE Transactions on industrial electronics, vol. 64, no. 4, pp. 2654-2662, 2016, doi: 10.1109/TIE.2016.2637303

14. Gaiceanu, M., Solea R., Codres, B., and Eni, C., "Efficient DC drive system by using adaptive control," In 2014 International Conference on Optimization of Electrical and Electronic Equipment (OPTIM), pp. 381-388. IEEE, 2014, doi: 10.1109/OPTIM.2014.6850961.

15. A. D. I. Napoli, "An approach to dc motor modeling and parameter calculation using finite element analysis and tensor mathematics," IEEE Trans. Power Appar. Syst., vol. PAS-102, no. 8, pp. 27992804, 1983, doi: 10.1109/TPAS.1983.317963.

16. J. Suriano and C. M. Ong, "Modeling of electromechanical and electromagnetic disturbances in DC motors," Natl. Symp. Electromagn. Compat., pp. 258-, 1989, doi: 10.1109/isemc.1965.7565338. 
17. Héctor Vicente Martínez Martínez, "Análisis, modelado y simulación en computadora del motor de corriente directa tipo serie," Universidad Tecnológica de la Mixteca, 2009.

18. PADRE-ÑONTHE, Juan David, RAMOS-FERNÁNDEZ, Julio Cesar, MÁRQUEZ-VERA Marco Antonio, "Modelado difuso T-S de un motor de CD y diseño de una estrategia de control PI difuso con ganancias programables," Rev. del Diseño Innov., vol. 1, no. 1, pp. 44-52, 2017.

19. I. Gottlieb, "Practical Electric Motor Handbook”. Butterworth-Heinemann, 1997.

20. S. J., Chapman, “Máquinas eléctricas," Quinta ed. Mc Graw Hill. 2012.

21. Kaye, J., and Gouse, S. W., "Thermal Analysis of a Small DC Motor; Part I. Dimensional Analysis of Combined Thermal and Electrical Processes [includes discussion]", Transactions of the American Institute of Electrical Engineers. Part III: Power Apparatus and Systems, vol. 75, no. 3, pp. 1463-1467, 1956, doi: 10.1109/AIEEPAS.1956.4499460.

22. Kaye, J., Gouse, S. W., and Elgar, E. C., "Thermal Analysis of a Small DC Motor; Part II. Experimental Study of Steady-State Temperature Distribution in a DC Motor with Correlations Based on Dimensional Analysis [includes discussion]". Transactions of the American Institute of Electrical Engineers. Part III: Power Apparatus and Systems, vol. 75, no. 3, pp. 1468-1486, 1956, doi: 10.1109/AIEEPAS.1956.4499461.

23. Acarnley, P. P., and Al-Tayie, J. K., "Estimation of speed and armature temperature in a brushed DC drive using the extended Kalman filter," IEEE Proceedings-Electric Power Applications, vol. 144, no. 1, pp. 13-20, 1997, doi: 10.1049/ip-epa:19970927.

24. Lin, C. J., Yau, H., T., and Tian, Y., C., "Identification and compensation of nonlinear friction characteristics and precision control for a linear motor stage," IEEE/ASME Transactions on Mechatronics, vol. 18, no. 4, pp. 1385-1396, 2012, doi: 10.1109/TMECH.2012.2202679.

25. Maeda, Y., and Iwasaki, M., "Initial friction compensation using rheology-based rolling friction model in fast and precise positioning," IEEE Transactions on Industrial Electronics, vol. 60, no. 9, pp. 38653876, 2012, doi: 10.1109/TIE.2012.2205350.

26. Ahmad, S., Zhang, H., \& Liu, G. (2012). Multiple working mode control of door-opening with a mobile modular and reconfigurable robot. IEEE/ASME Transactions on Mechatronics, vol. 18, no. 3, pp. 833844, 2013, doi: 10.1109/TMECH.2012.2191301.

27. S. Jatsun, A. Malchikov and A. Yatsun, "Adaptive Control System for DC Electric Drive under Uncertainty," 2020 International Conference on Industrial Engineering, Applications and Manufacturing (ICIEAM), pp. 1-5, 2020, doi: 10.1109/ICIEAM48468.2020.9111876.

28. M. A. Taut, G. Chindris, A. C. Taut and D. Pitica, "Model-in-the-Loop for Determining the Speed and Position of a DC Motor," 201841 st International Spring Seminar on Electronics Technology (ISSE), pp. 1-7, 2018, doi: 10.1109/ISSE.2018.8443767.

29. Gieck, K., “Manual de fórmulas técnicas” 33 ed. México: Alfaomega. 2017.

30. ChemicalSafetyFacts, "Poliestireno," Get chemical safety information on the products you use every day, 2021. [Online]. Available: https://www.chemicalsafetyfacts.org/es/poliestireno/. [Accessed: 02Apr-2021]. 
31. J. U. Liceaga-castro, I. I. Siller-alcalá, J. Jaimes-ponce, R. A. Alcántara-ramírez, and E. A. Zamudio, "Identification and Real Time Speed Control of a Series DC Motor," Math. Probl. Eng., vol. 2017, p. 11, 2017, doi: doi.org/10.1155/2017/7348263.

32. C. May, C. Creayla, F. Carlo, C. Garcia, E. Queen, and B. Macabebe, "Next Day Power Forecast Model Using Smart Hybrid Energy Monitoring System and Meteorological Data," Procedia - Procedia Comput. Sci., vol. 105, no. December 2016, pp. 256-263, 2017, doi: 10.1016/j.procs.2017.01.219.

33. H. Chaudhary, "ANFIS Based Speed Control of DC Motor ANFIS Based Speed Control of DC Motor," 2016 Second Int. Innov. Appl. Comput. Intell. Power, Energy Control. with their Impact Humanit., vol. 16, pp. 63-67, 2016, doi: 10.1109/CIPECH.2016.7918738.

34. Z. Sen, G. U. Wanli, H. U. Yunfeng, D. U. Juan, and C. Hong, "Angular Speed Control of Brushed DC Motor Using Nonlinear Method: Design and Experiment," Proc. 35th Chinese Control Conf., pp. 10451050, 2016, doi: 10.1109/ChiCC.2016.7553225.

35. K. Kroics and R. Geidarovs, "Practical Method for Experimental Detection of DC Motor Inertia to Design a Speed Regulator," Adv. Information, Electron. Electr. Eng. AIEEE 2019 - Proc. 7th IEEE Work., vol. 2019-November, no. 5, 2019, doi: 10.1109/AIEEE48629.2019.8977095.

\section{Figures}

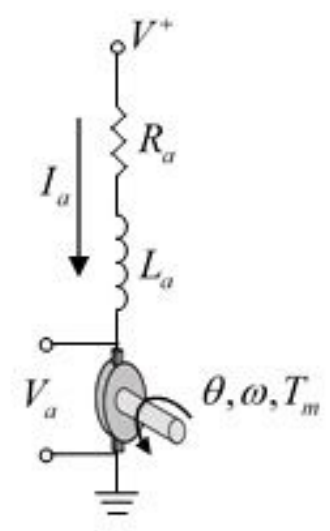

\section{Figure 1}

Equivalent circuit of brushed direct current motor. 
a)

b)

\section{Figure 2}

Adiabatic system of a BDCM: a) front view of the instrumented system, $\boldsymbol{b}$ ) top internal view of the case, and c) right external side view of the case. 


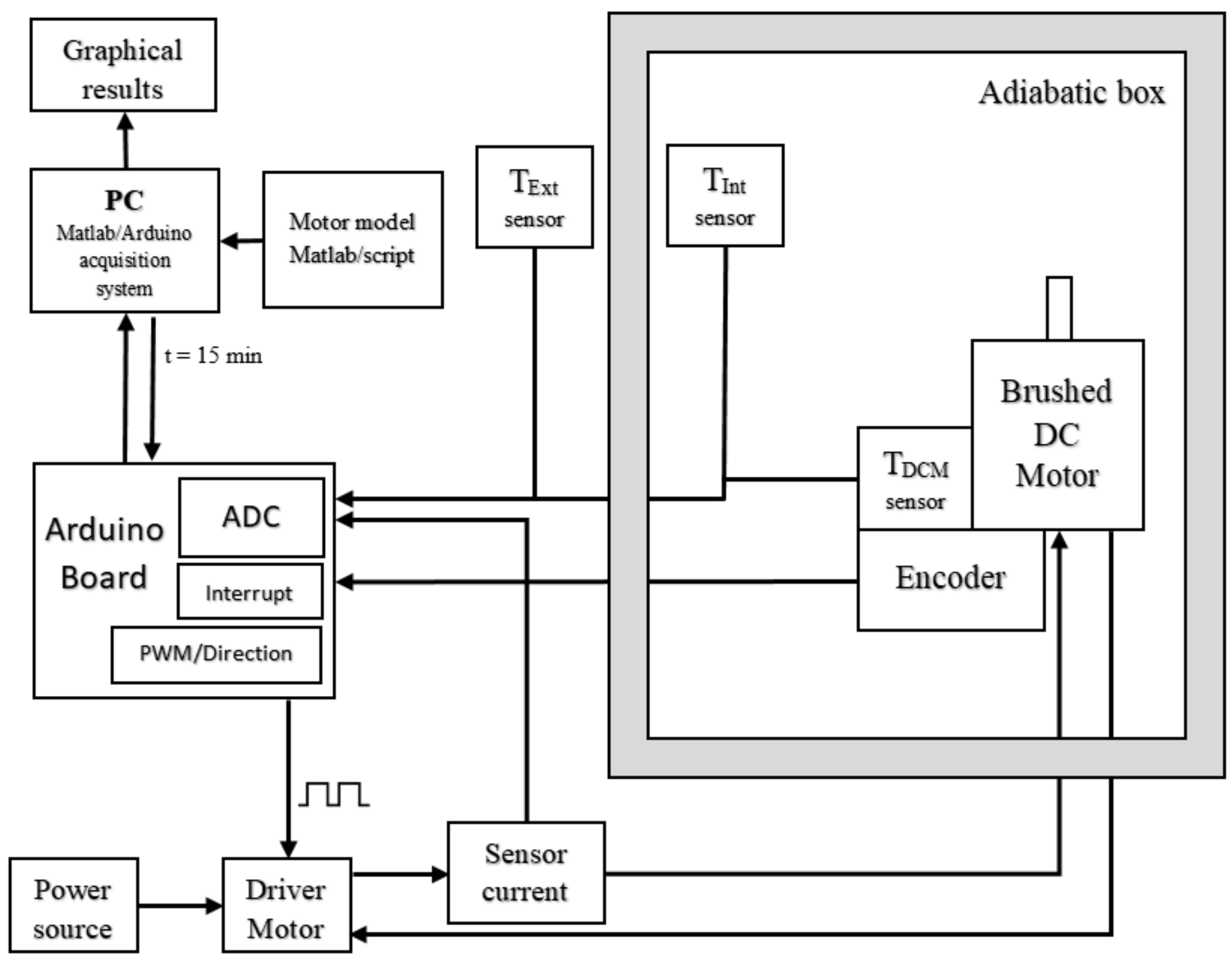

Figure 3

Data acquisition scheme of the adiabatic system of a BDCM. 

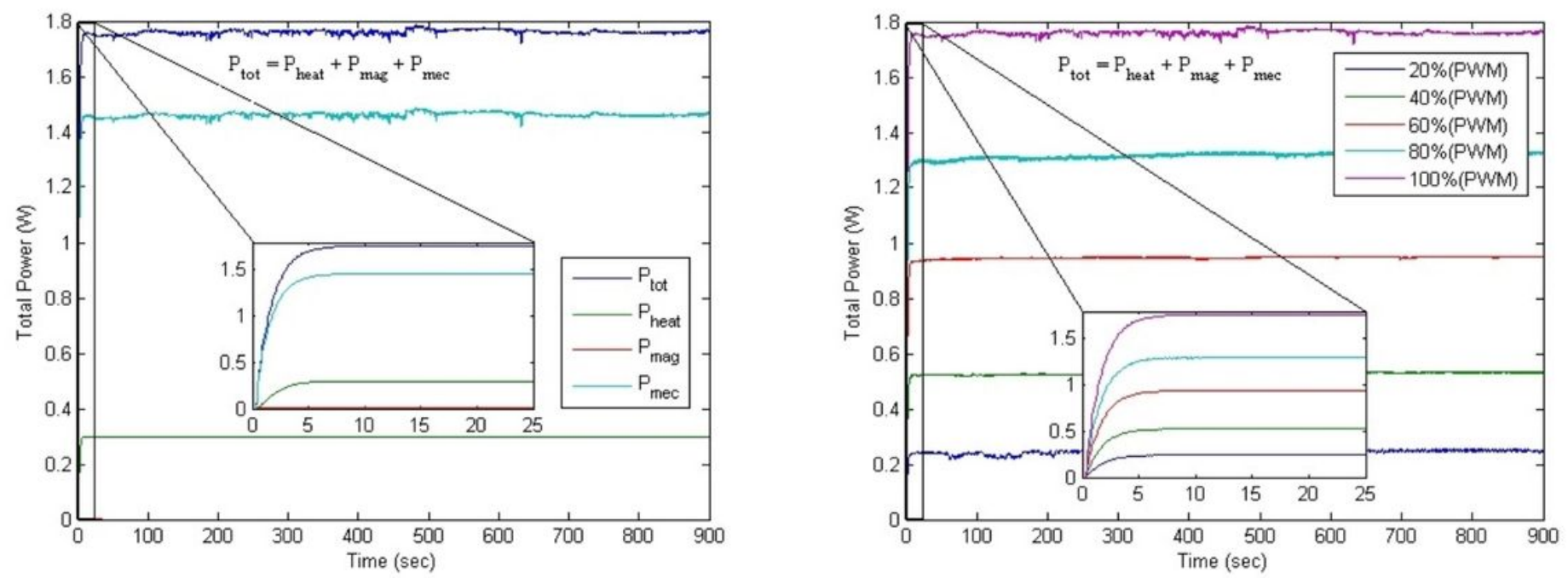

Figure 4

Estimation of the total electrical power $(P)$ : a) the contribution of the electrical, mechanical, and magnetic powers at $100 \%$ of PWM and $\boldsymbol{b}$ ) the transitory during operation at $20,40,60,80$, and $100 \%$ of the PWM rated capacity.
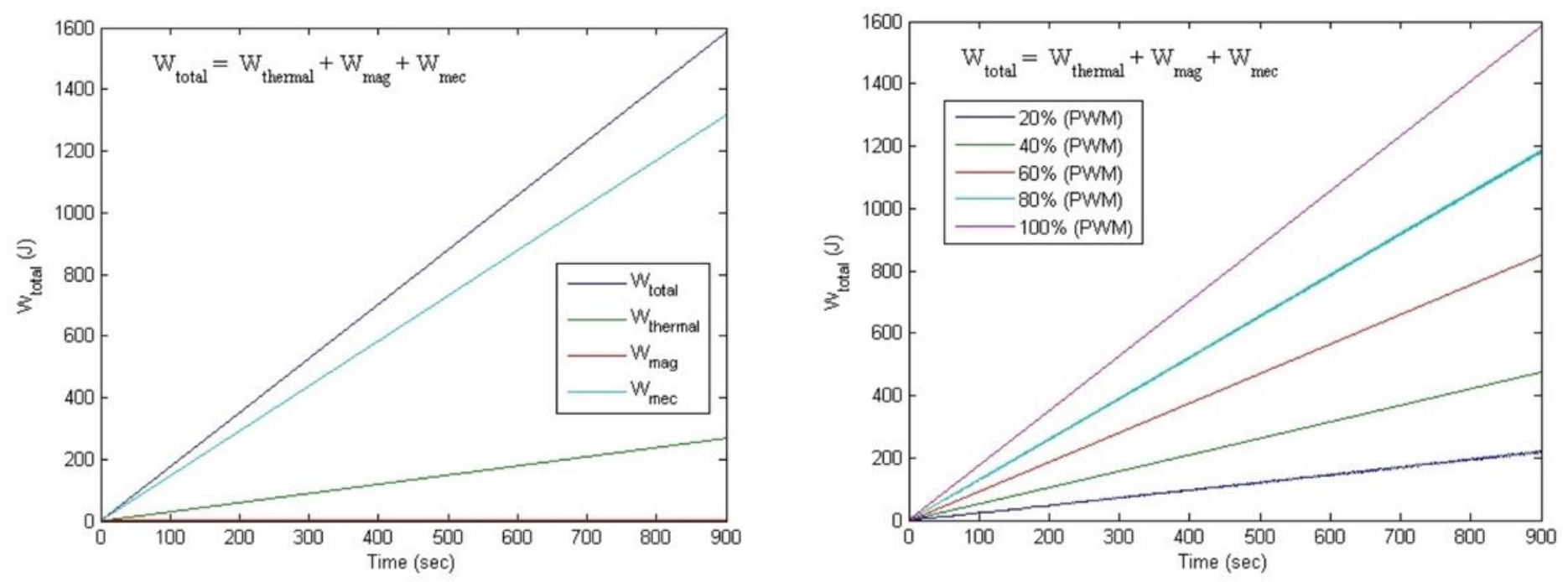

\section{Figure 5}

Estimation of total work (W): a) the contribution of electrical, mechanical, and magnetic powers at $100 \%$ of PWM and $\boldsymbol{b}$ ) the transitory during operation at $20,40,60,80$, and $100 \%$ of PWM rated capacity. 

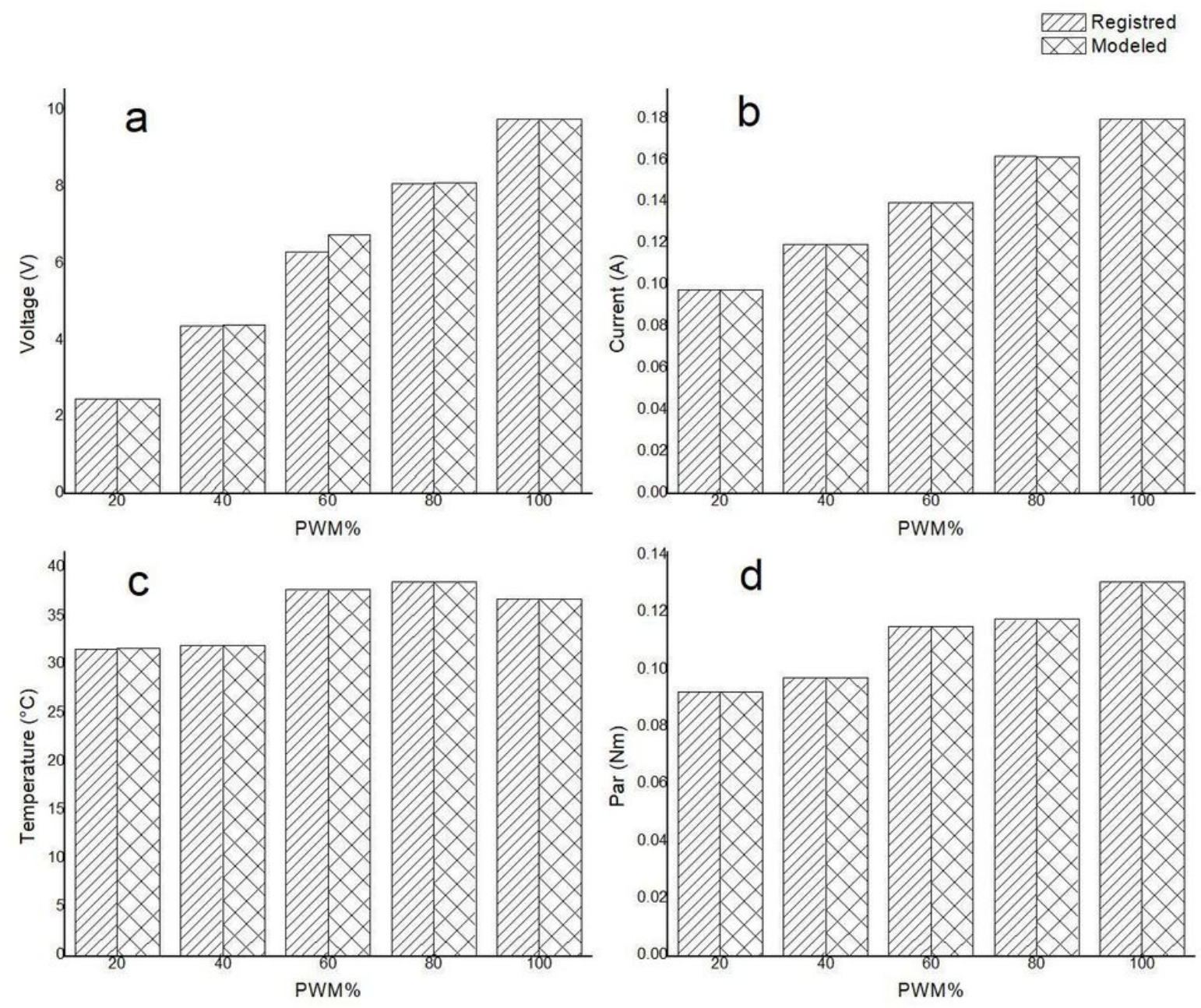

\section{Figure 6}

Comparison between the response of the adiabatic BDCM system and the value estimated by the mathematical model of the voltage (a), current (b), temperature (c) and torque (d). During operation at 20, $40,60,80$, and $100 \%$ of the PWM rated capacity. 


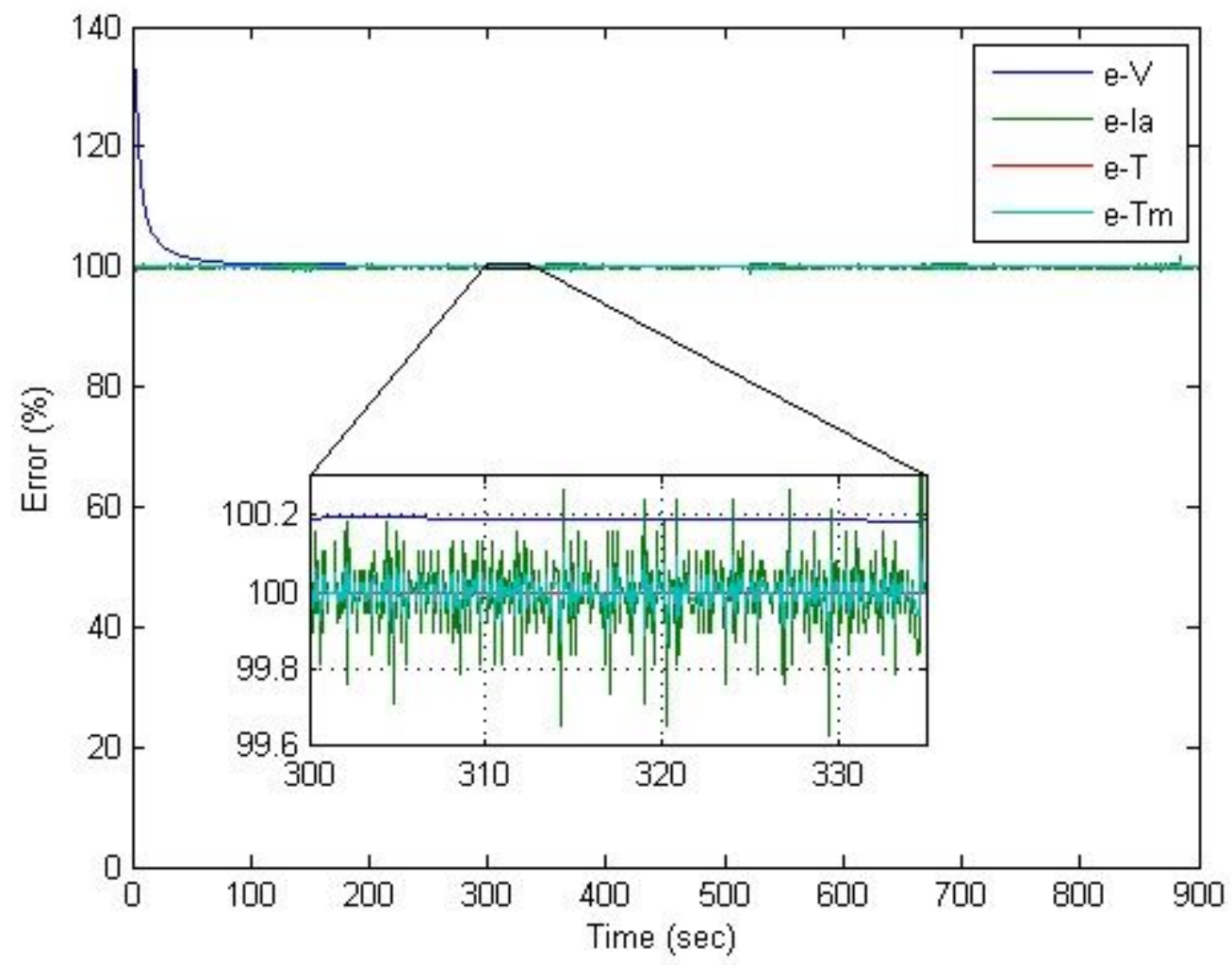

Figure 7

Percentage accuracy of the measured variables and the calculated mathematical model of voltage (Blue), current (Green), temperature (Red), and torque (Cyan), during operation at $100 \%$ of the PWM rated capacity. 


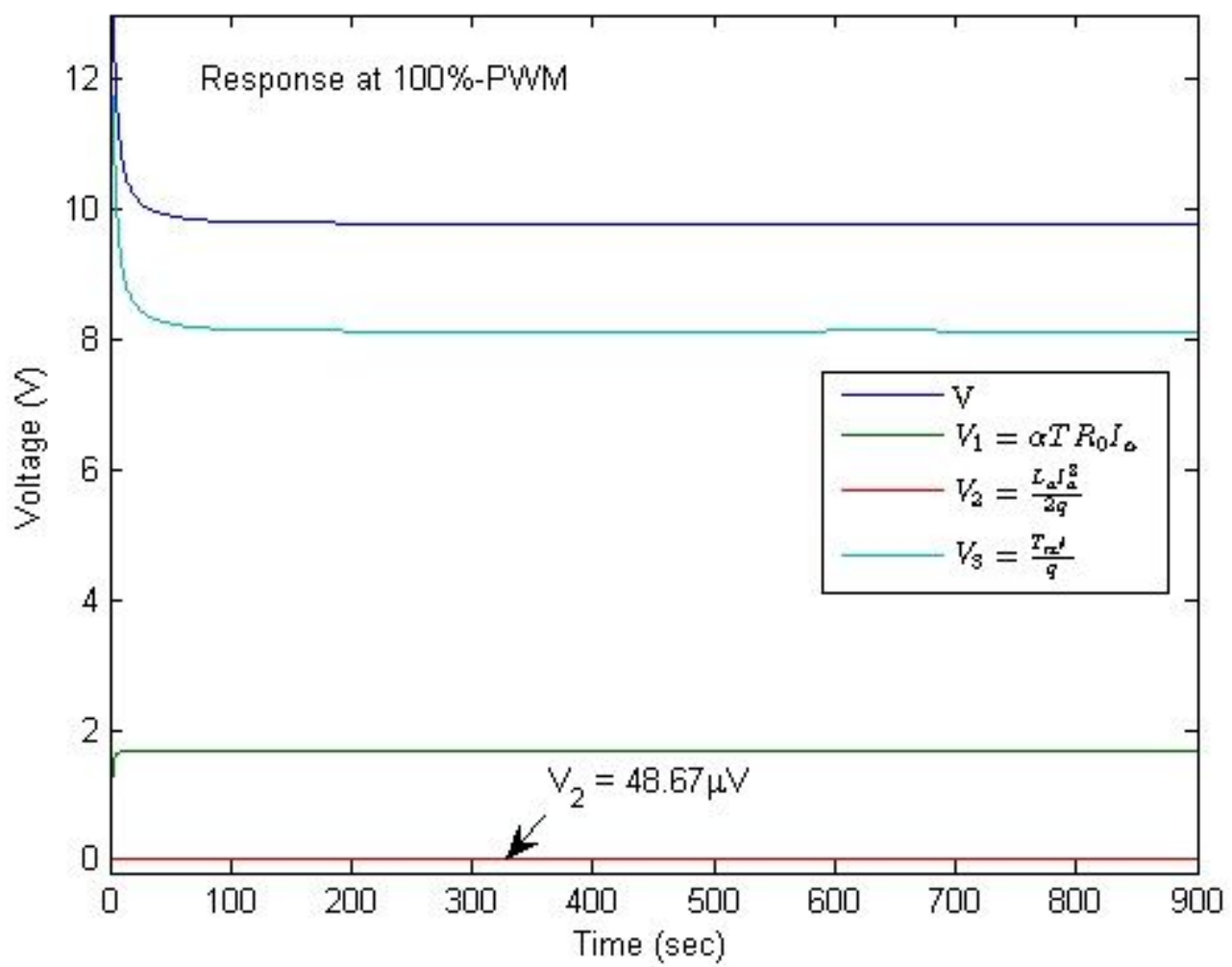

Figure 8

Comparison between voltage and electrical, magnetic, and mechanical contribution, during operation at $100 \%$ of the PWM rated capacity. 


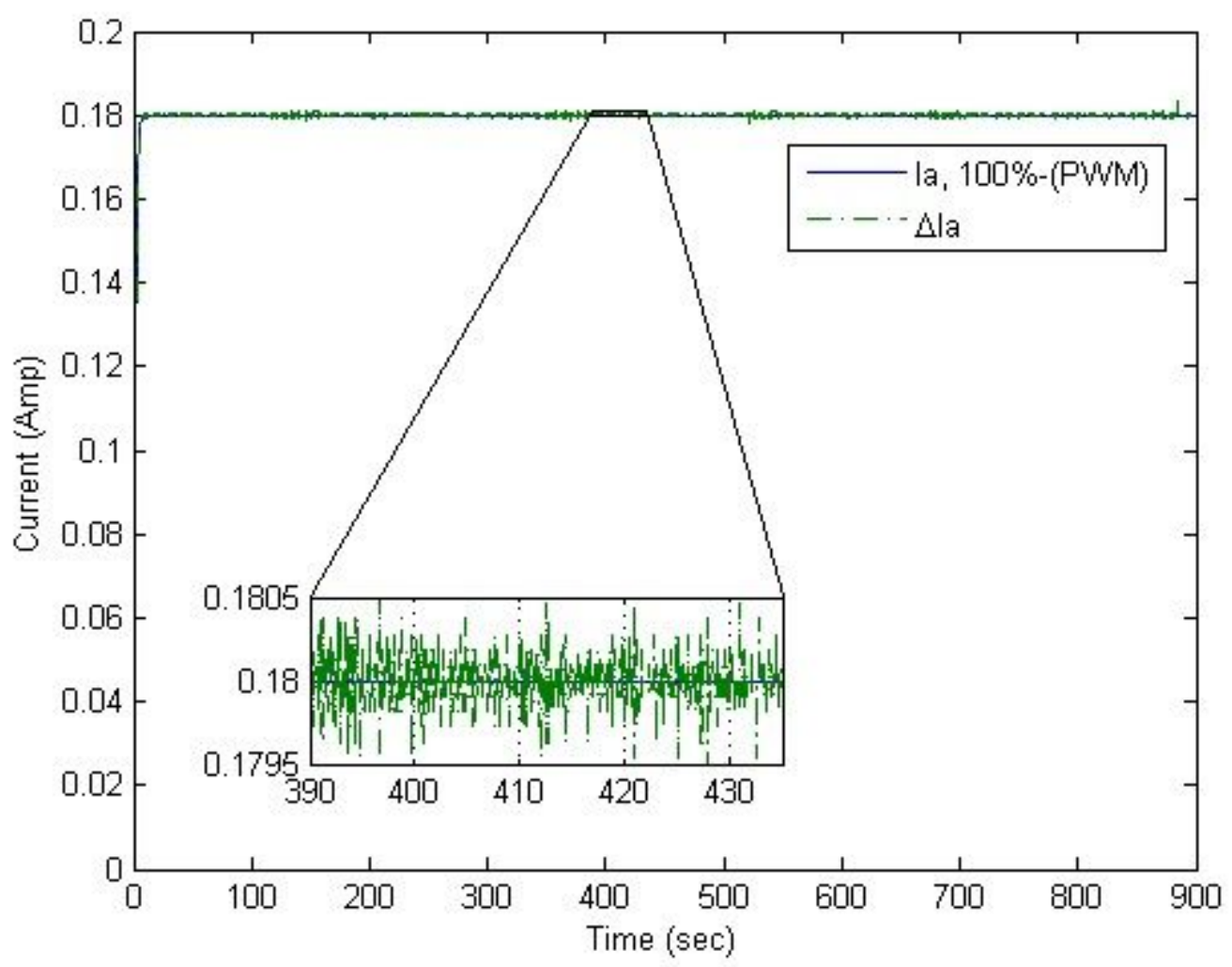

Figure 9

Comparison between the measured and calculated current using the mathematical model, as well as the electrical, magnetic, and mechanical contribution, during operation at $100 \%$ of the PWM rated capacity. 


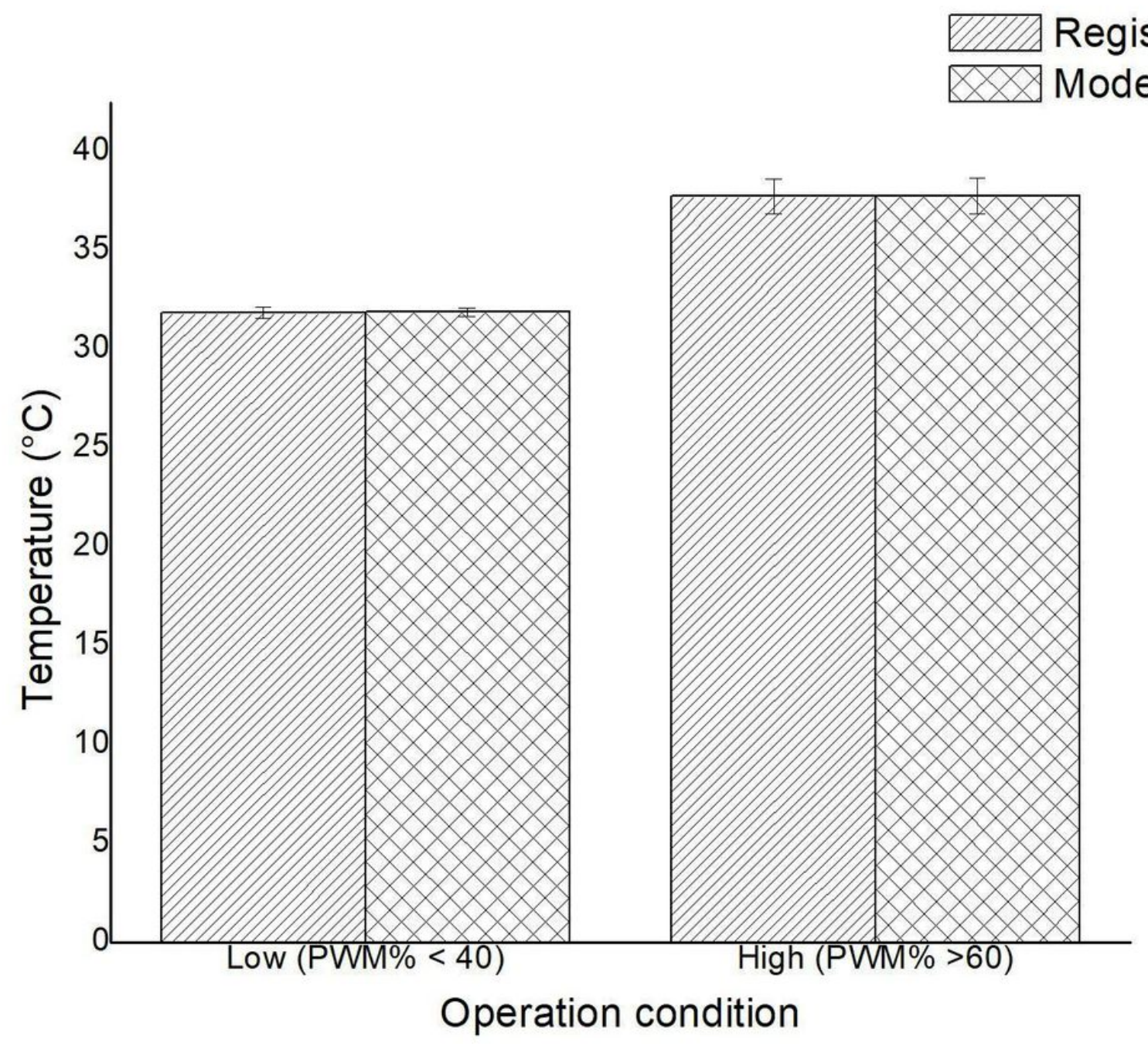

Figure 10

Comparison between the calculated and measured BDCM operating temperature at two possible operating conditions of the PWM rated capacity: Low for PWM\% values $<40$ and High for PWM\% values $>60$. 


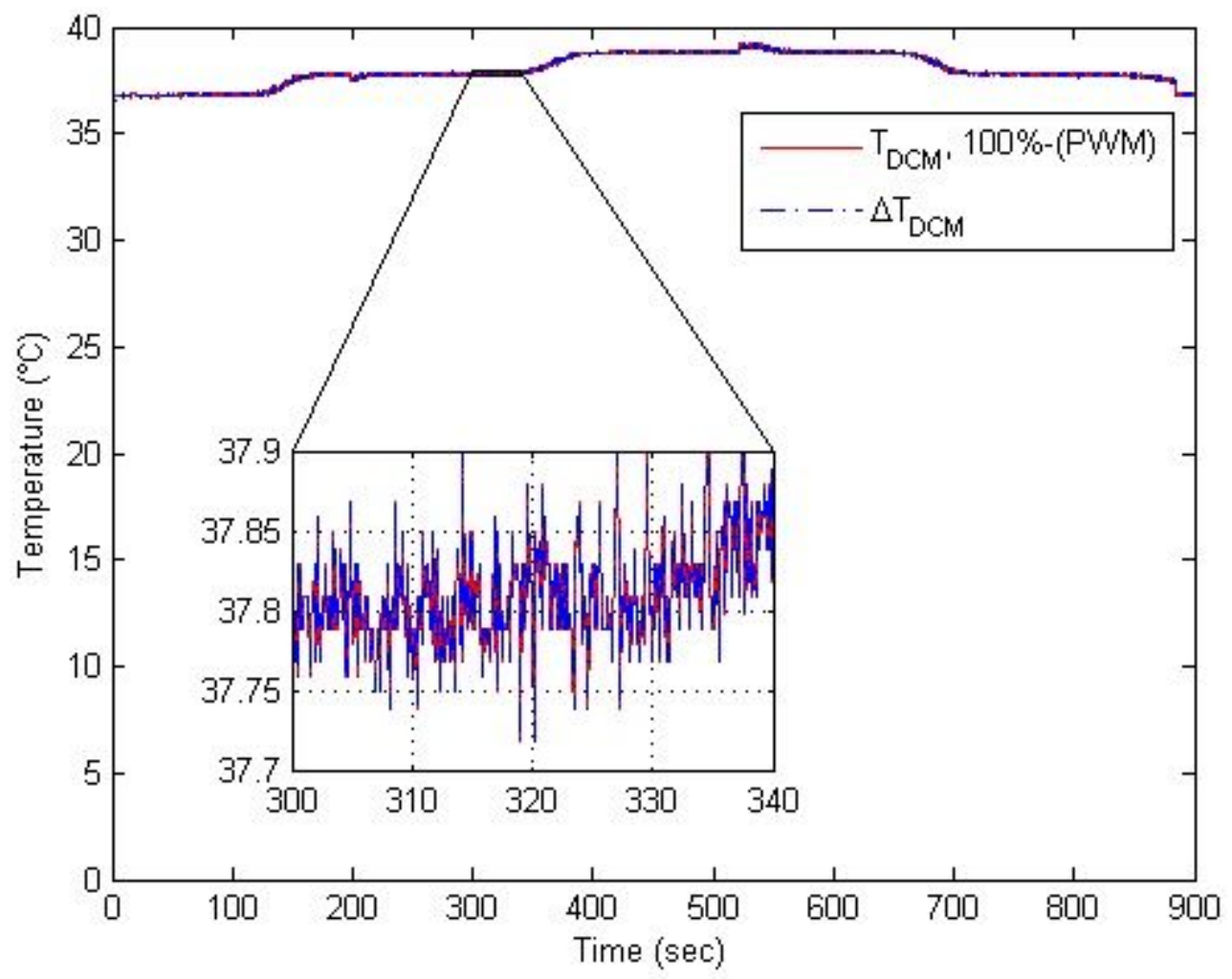

Figure 11

Comparison between the calculated temperature of the BDCM using the mathematical model and the measured one, during operation at $100 \%$ of the PWM rated capacity. 


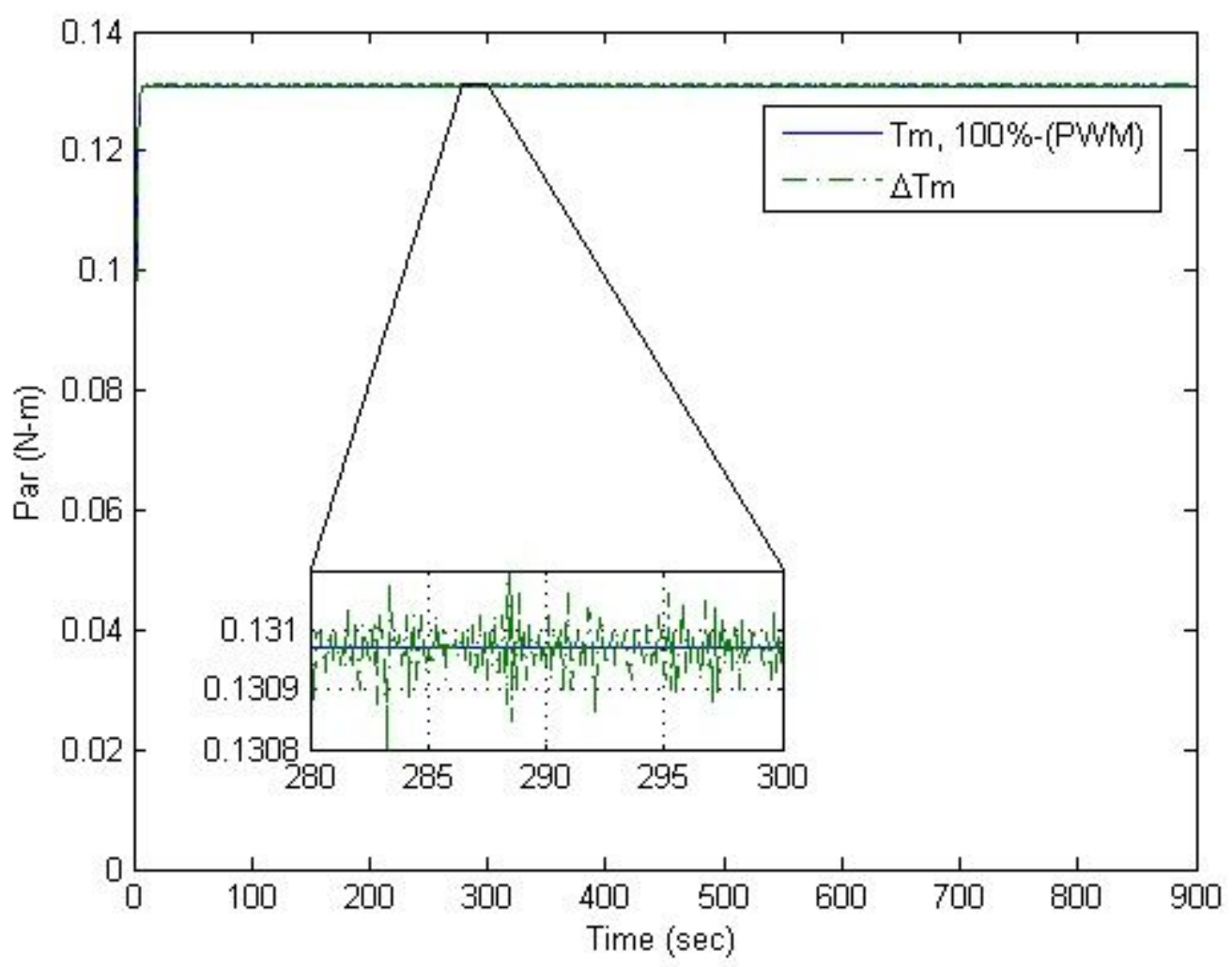

Figure 12

Comparison between the measured and calculated torque using the mathematical model, as well as the electrical, magnetic, and mechanical contribution, during operation at $100 \%$ of the PWM rated capacity. 